\title{
Medikal Endüstride Yapay Zeka ve Uzman Sistemlerin Sürekli İyileştirmeye Etkisi
}

\author{
Muharrem ÜNVER*, Ceren ALTUNOK* \\ *Karabük Üniversitesi, Mühendislik Fakültesi Endüstri Mühendisliği Bölümü, Karabük, Türkiye
}

\section{ÖZET}

Bu çalışma, medikal alanda üretim yapan bir firmada "Serebral Palsi" hastalığıyla mücadele eden çocuklar için üretilen yürüteçlere yönelik olarak yapılmıştır. Sorun; yürüteçlerin yapım aşamasındaki montaj hattında çıkan vidalama sorunudur. Yürüteçler firmamızda çeşitli hatlardan parçalar halinde gelerek montaj hattımızda insan gücüyle birleştirilmekteydiler. Bu yürüteçlerde çok fazla parça ve parçaları birleştirmek için çok fazla materyal kullanmamızdan dolayı insan gücünün montaj kısmında yetersiz kalarak hatalara yol açtığı görülmüştür. Montaj hattından çıkan bazı parçaların zayıf takılmış, çizilmiş olması kalite standartımızı kötü etkilemekteydi. Bundan dolayı gerekli araştırmalar yapıldıktan sonra montaj hattının insan operatörlerle koordineli çalışarak makineleştirilmesi kararlaştırılmıştı. Sonuçlara göre montaj hattının verimlilik düzeyi firmamızdaki en düşük verimlilik oranına sahipken projenin başarıya ulaşmasıyla firmamızdaki en iyi hat/tezgahlardan biri haline gelmiştir. Bu değişimin maddi ve mühendislik kazanımları dikkate alınarak gelecekte karşımıza çıkabilecek sorunlar konusunda başarılı bir yol haritası çizmemize yardımcı olmuştur.

Anahtar Kelimeler: yapay zeka, uzman sistemler, esnek üretim hattı

\begin{abstract}
This study was conducted for walkers produced for children struggling with "Cerebral Palsy" in a company that manufactures in the medical field. Problem; It is the screwing problem in the assembly line of the walkers under construction. Walkers came in pieces from various lines in our company and were combined with manpower in our assembly line. In these walkers, it has been observed that because we use too many parts and too much material to join the parts, the manpower is insufficient in the assembly part and is causing errors. The fact that some parts coming off the assembly line were poorly fitted or scratched had a bad influence on our quality standard. Therefore, after the necessary researches, it was decided to mechanize the assembly line by working in coordination with human operators. According to the results, while the efficiency level of the assembly line has the lowest efficiency rate in our company, it has become one of the best lines/machines in our company with the success of the project. Taking into account the material and engineering gains of this change, it has helped us to draw a successful roadmap for problems that may arise in the future.
\end{abstract}

Keywords: artificial intelligence, expert systems, flexible production line

*Corresponding author: Address: Faculty of Engineering, Department of Industrial Engineering Karabuk University, 78050, Karabuk TURKEY. E-mail address: cerennnaaltunok@ outlook.com , Phone: +905366227523 


\section{GİRIŞ}

Günümüzde gelişen teknoloji ile birlikte üretimde esneklik sağlanırken aynı zamanda hızın ve verimlilik artışının ortaya çıktığı gözlenmektedir. Esnek imalat sistemleri, üretilen ürünlerin, farklılaşan ürün çeşitliliğine ve üretim yöntemlerine hızlı bir şekilde entegre edilebilen bir üretim sistemidir. Üretim zaman içinde gelişerek; daha otomatik, bilgisayarlı ve karmaşık bir hale gelmiştir. Akıllı üretim, bugünün ve yarının üretim varlıklarını sensörler, bilgi işlem platformları, iletişim teknolojisi, kontrol, simülasyon, veri yoğun modelleme ve tahmine dayalı mühendislik ile bütünleştiren yeni bir üretim şeklidir. Nesnelerin interneti, bulut bilişim, hizmet odaklı bilişim, yapay zeka ve veri bilimi tarafından yönlendirilen siber-fiziksel sistemler kavramlarını kullanır. Bu kavramlar ve teknolojiler bir kez uygulandığında akıllı üretimi bir sonraki sanayi devriminin damgası haline getirecektir. Akıllı üretimin özünde; altı sütun, üretim teknolojisi ve süreçleri, malzemeler, veriler, tahmine dayalı mühendislik, sürdürülebilirlik ve kaynak paylaşımı ve ağ oluşturmada ele alınmaktadır.

Esnek üretim sistemlerinin tanımlarını inceleyecek olursak; esnek üretim sistemleri, merkezi bilgisayar tarafından kontrol edilen, otomatik taşıma sistemleriyle birbirine bağlanmış ve iş istasyonlarıyla desteklenen otomatik nümerik kontrollü takım tezgahlarının oluşturduğu üretim sistemleridir. Esnek üretim kavramı üç temel üretim alt sistemine uygulanmıştır. Bu sistemler; imalat, işleme ve montaj sistemleridir. [9]

Esnek üretim sistemleri, farklı parça ve ürünleri önemli bir değişiklik ya da tezgah duruşuna gerek kalmaksızın, üretebilme kabiliyeti olan sistemlerdir. [10]

Esnek işleme sistemleri, uygulayıcılar geliştirilen sistem sayısına göre ölçülmüştür ve araştırmacılar arasında büyük ilgi görmüştür. Bunun nedeni, imalat sanayinde işlemenin önemi ve takım tezgahları teknolojisindeki ilerlemeden kaynaklanıyor olabilir. Başlangıçta esnek montaj sistemleri oldukça az ilgi görmesine rağmen, son birkaç yıldır ilgi hızla artmaktadır. Esnek üretim sistemleri az ilgi çekmiştir, ancak esnek teknoloji uygulamaları için büyük bir potansiyel oluşturmaktadır. Bu üç alt sistem tarafindan üretilen en zor problemlerden biri de programlama problemidir.

\section{YAPAY ZEKA UZMAN SİSTEMLERİN KULLANIM ALANLARI}

Yapay zeka; akıl ve düşünmeyi sağlayan sürecin bilgisayarlar sayesinde yapılabilmesini sağlayarak araştırmalar ve yeni yöntemleri geliştirmeyi amaçlayan bir daldır.[6] O halde yapay zeka; bir bilgisayar kontrollü makinanın, genellikle insana özgü nitelikler olduğu varsayılan akıl yürütme, 
anlam çıkartma, genelleme ve geçmiş deneyimlerden öğrenme gibi yüksek zihinsel süreçlere ilişkin görevleri yerine getirme yeteneği olarak tanımlanabilir. [4]

Yapay zeka, bilgisayarlar üzerinde insanın zekasını taklit etmeye dayanarak geliştirilmiştir. Uzman sistemler, belirlenen problemin çözümü ile ilgili bir veya daha fazla uzmanın bilgi ve becerisini kullanan bilgisayar sistemidir.[7] Yapay zeka çok kapsamlı bir bilgi havuzundan yararlanır ve insanın yaptığı zeka gerektiren davranışları bilişim ağının yapmasıdır.[1] Bunun yanında karışık problemleri kısa bir sürede çözmede yarar sağlayarak zaman kazandırır.

İmalat sektöründe bir dizi ilginç hesaplama probleminin basit bir üretim tekniği olarak yapay zeka sorunların birçoğu, geleneksel hesaplama teknikleri olarak düşünülebilecek şeyleri gerektiren sayısal niteliktedir. Ancak sorunların önemli bir alt kümesi kombinatoryal karmaşıklığ iç̧erir. Her ne kadar bu ikinci problemler üretim fonksiyonlarına gider eklerken güçlü bir şekilde yer alsa da, onlar için hesaplama çözümlerine biraz çaba harcanmıştır. Bir disiplin olarak hesaplamanın başlangıcından bu yana, bir dizi problem sınıfı oldukça iyi anlaşılmıştır. Bilgisayarların günümüzdeki en büyük uygulaması bu sınıflara giren sayısal olarak zor veya hesaplama olarak sıkıcı sorunları çözmektir. Bilgisayarlar bu sorunların otomatik çözümü yoluyla yaşamlarımız üzerinde muazzam bir etkiye sahiptir.

Yapay zeka John Searle tarafından "YZ" araştırmacılarına atfettiği iki hipotez şekilde ayrılmaktadır. Bunlar; güçlü yapay zeka ve zayıf yapay zeka olarak ayrılmıştır. [3]

2.1 Güçlü Yapay Zeka: Güçlü yapay zekanın arkasındaki prensip düşünmektir. Başka bir deyişle ifade etmek gerekirse gelecekteki insan zihni olarak tanımlanabilir. Böylece, yakın gelecekte bu tür tamamen insan gibi çalışabilen makine veya makine insan seviyesinde bir zekaya sahip olabilir. $\mathrm{Bu}$ sayede bu makineler bir insanın tüm işlevlerini yapabilirler.

2.2 Zayıf Yapay Zeka: Zayıf yapay zekanın arkasındaki prensip, makinelerin akıllıymış gibi davranabileceği gerçeğidir. Makinelerin insan düzeylerinde akıllı davranış sergileyecek şekilde programlanabileceği hipotezidir. Örneğin; bir insan oyuncu bir bilgisayara karşı satranç ya da kart oynadığında, insan oyuncu bilgisayara etkileyici hamleler yapıyor. Ama bilgisayar hiç düşünmüyor ve planlamıyor. Yaptığı tüm hareketler daha önce bilgisayara bir insan tarafından besleniyor ve bu yazılım bu şekilde doğru zamanda doğru bir şekilde hareket edebiliyor.

$\mathrm{Bu}$ çalışma, problemlerin çözümlerinde kombinatoryal karmaşıklı̆̆ı içermemektedir. Sayısal olarak zor olabilir, matematiksel yaratıcılık ve programlama becerileri gerektirebilirler. İkincisi, genellikle bu sorunlar için iyi bilinen, nispeten standart bir çözüm süreci vardır. Bazı durumlarda süreçler insanlar tarafından bilgisayarlardan önce yaygın olarak kullanılmaktaydı ve bu durum makineye aktarıldıkça gelişti. Bu gerçekleşme, yapay zekanın başlangıcını bilgisayar biliminin bir kolu olarak işaretlemiştir. Bu tartışmanın amaçları için yapay zeka, doğal bir fenomen, insan bilişsel yeteneği, yapay bir benzetme, bilgisayar programları ile ilişkilendiren bilgisayar biliminin deneysel dalı olarak düşünülebilir.

\section{MATERYAL ve METOT}


Uzman Sistemler, yapay zekanın sahip olduğu alt dallardan biridir.[7] Bir uzman sistem, belirlenen problemin çözümü ile ilgili bir veya daha fazla uzmanın bilgi ve becerisini kullanan bir bilgisayar sistemidir.[8]

İmalat sürecinde kullanılan teknik ekipmanlar ve bunları kullanırken faydalanılan "Uzman Sistem Altyapısı" değerlendirilen materyaller olarak karşımıza çıkmaktadır.

İmalat süreçlerinde ortaya çıkan sorunları çözmek ve gerekli iyileştirmeleri yapmak üzere oluşturulan matematiksel modellemeler ve bunların bilgisayarda ele alınma şekli kullandığımız yöntemler olarak dikkat çekmektedir.

Üretim birçok şekil ve boyutta gerçekleşir. Sürekli üretim, ayrık üretim, proje tipi üretim ve atölye tipi üretim olarak 4 ana kategoridir. [5] Örneğin; bir kimya fabrikasında bulunan türün sürekli üretimi daha fazla tartışılmayacaktır. Ayrık imalatın birçok alt kategorisinden sadece bir tanesi tartışma amacıyla kullanılmaktadır. Seçim alanı, mekanik ürünlerin yani esas olarak üç boyutlu sert parçalardan üretilen ürünlerin imalatıdır. Bisiklet, otomobil, bulaşık makinesi, çamaşır makinesi buna iyi örneklerdir.

Elektrikli / elektronik ürünlerin ayrı üretimi veya sürekli kimyasal ürünlerin imalatı gibi işlemler, hesaplama tekniklerinin uygulama alanları olarak görülemez. Basitçe, ayrı mekanik üretimin, çoğu hedeflenen kitlenin deneyimi dahilinde zengin bir örnek kaynağı olarak seçildiği anlamına gelir.

Ayrık mekanik üretim ve ilişkili mühendislik fonksiyonlarını hesaplama problemleri olarak tartışmak için basit (fakat aşırı basitleştirilmemiş) bir model önerilmektedir. Bu model; parça tasarımı aşaması, proses tasarımı aşaması ve proses yürütme aşaması olmak üzere üç aşamadan oluşur. Bu aşamaların her birinde, ortaya çıkan problemler değerlendirilirken, matematiksel modellemelerle sonuca ulaşılmaya çalışılmıştır.

Ayrık üretim; parça tasarımı, süreç tasarımı ve süreç yürütme olarak 3'e ayrılmaktadır.

\subsection{Parça Tasarımı İmalat Aşaması}

Parça tasarımındaki ilk adım, hem sentez hem de analizle ilgilenen kavramsal bir adımdır. Burada ürünün tasarım açısından temel fikirleri üretilir ve test edilir. Bu adımda birçok kısıtlama vardır. Ürün planlama işlevinden belirli bir işlev grubuna her biri için bir performans seviyesine ve pazardaki paketlenmiş satış fiyatına sahip bir ürün talebi gelir. Yönetim işlevinde; yanıt verirken aşılmaması gereken tasarım ve geliştirme bütçeleri gelir. Kavram sentezinin amacı, bu çeşitli kısıtlamaları ve ürün kısıtlamalarını dayatmaktır.

Parça tasarımı, ayrıntılı inceleme için mühendislik mikroskobu adı altında da açıklanmıştır. Kavram sentez fazına girilen aynı kısıtlamaların hepsi detay sentez fazına genişletilmiş biçimde geçirilir. Örneğin; konsept sentezi için başlangıçta ürün planlamasından girilen istenen özellik ve işlevlerin listesi artık bir kullanım kılavuzu ve bir bakım kılavuzu düzeyinde ayrıştırılmış belirtilmiş belgelenmiş ve incelenmiştir. Detay analizi, kavramsal adımın kaba analizinin aksine, ürünün çeşitli beklenen çalışma koşullarını simüle eden genişletilmiş hesaplamalarla ilgilidir.

\section{2. İmalatta Süreç Tasarımı}


Süreç Tasarım Aşaması, parça tasarım aşaması ile yüksek derecede benzerlik gösterir. Ancak dikkatin odak noktası imalat parçalarının üretildiği tasarımların tasarlanması üzerinedir. Sürecin ilk adımı ürünün üretim açısından temel fikirlerinin üretildiği ve test edildiği kavramsal bir adım tasarlamayı içerir. Bu adıma girilen kısıtlamaların bir kısmı ayrıntılı ürün spesifikasyonu biçiminde "Parça Tasarımı Aşamasından" gelmektedir. Diğer önemli kısıtlamalar, aslında fabrika katında bulunan üretim tesislerinden ve malzeme, alet ve parça envanterinden kaynaklanmaktadır. Bir kez daha yönetim fonksiyonu, süreç tasarım aşamasında aşılmaması gereken zaman ve para bütçeleri şeklinde kısıtlamalar sağlar. Kavramsal sentez aşamasının amacı bu kısıtlamaları ve mühendislik kuralları ve doğa yasaları tarafından dayatılan bir çözüm yaratmak yani kavramsal bir süreç tasarımıdır. Kavram analizi aşamasının amacı, bu kavramları fizibilite açısından test etmektir.

Süreç tasarım aşaması sırasında, bir dizi yapım veya satın alma kararı verilir. Bir parça (veya araç) satın almak mümkünse ve maliyeti sürecin tasarımı bağlamında makul ise, parça (veya araç) siparişleri verilmeli ve teslimatlar kısıtlama olarak girilmelidir. Öte yandan, parçalar (veya aletler) şirket içinde daha etkili bir şekilde yapılırsa malzeme siparişleri verilmeli ve ortaya çıkan kısıtlamalar dikkate alınmalıdır. Proses tasarım aşamasının sonucunun ön koşulu, proses uygulama aşamasına geçmek için ayrıntılı bir üretim spesifikasyonudur.

\subsection{Imalatta Süreç Yürütme Aşaması}

Ürün ayrıntılı olarak tasarlandıktan ve üretim süreci ayrıntılı olarak planlandıktan sonra, bir sonraki belirli aşama, ürünü yapmak için sürecin gerçekleştirilmesidir.

Zhang ve ark. 1993 yılında, işleme prosesinin gerçek zamanlı izlenip kontrol edilmesi ile operatör becerisi ve kabiliyetine bağlı olmaksızın en uygun işlemenin başarılmasının mümkün olacağını bildirmiştir.

Link ve ark. 2001 yılında adaptif kontrol teknikleri, bulanık mantık, yapay sinir ağları ile kontrolör kazanç ataması konularında genel araştırma çalışması yapmışlardı. Bu çalışmada sensör tabanlı zeki karar destek sistemlerini kullanarak çevrimiçi izleme yapan sistem kurmuşlardır. [2]

Süreç uygulamasında ilk adım, hammadde ve malzemenin, parça üretmek için sayısal olarak kontrol edilen takım tezgahları gibi imalat ekipmanlarıyla bir araya getirilmesidir. Bu adım ayrıca parçaların bitirilmesini, incelenmesini veya test edilmesini ve gerektiğinde parçaların depoya yerleştirilmesini içerebilir. Süreç yürütmedeki ikinci adım, parçaları bir araya getirmeyi ve ürünleri monte etmek için sensör tabanlı robotlar gibi diğer üretim ekipmanlarıyla birlikte takımları içerir. Buna ek olarak, ürünün bitirilmesi, denetlenmesi, test edilmesi ve depolanması gerekir.

$\mathrm{Bu}$ imalat modelinde, paketleme işlevi bir tür genelleştirilmiş montaj ve ayrıca ürünün montajı olarak dahil edilmektedir. Hem detaylı ürün spesifikasyonunda hem de detaylı proses spesifikasyonlarında kapsüllenmiş proses, proses yürütme için girdi olarak kullanılır. Yönetim fonksiyonundan üretim zamanı ve maliyet bütçeleri gelir. Üretimin bu aşamasında doğa yasaları ön plana çıkmaktadır.

\section{UYGULAMA}


Uygulama CSM Medikal'in İstanbul'daki fabrikasında yapılmıştır. CSM firmamızın sorunu üretim hattında vidaların yeterince sıkı sıkılamamasından kaynaklanan parçaların birleşme yerlerinin ayrılması ve bu durumun sık yaşanması dolayısıyla üretim takvimde geride kalınması ve markanın kalite değerlerine zarar gelmesiydi. Öncelikle insan gücünü oradan çekerek yerine yapay zekalı bir robot koyulması gerektiğini anlaşılmıştı ancak şirkete bunun ne kadara mal olacağının araştırılması gerekiyordu.

Öncelikli olarak sorunlu üretim tezgahını ve diğer tezgahların verimlilik analizleri yaptırıldı. Yapılan verimlilik çalışmalarının ardından en çok sorun yaşanan (parça kalınlığının yanlış olması, personel bilgisizliği, yanlış montaj gibi) ilk 3 üretim hattı sırasıyla; vida sıkım (montaj tezgahı1), torna tezgahı ve boya tezgahı olarak belirlenmiştir.

$\mathrm{Bu} 3$ tezgahında ortak sorunu insan hatasından kaynaklanmış olmalarıydı. Vida sıkım tezgahında vidalar bol bırakıldığı için montaj tezgahı 2'ye geldiğinde parçaların birbirine oturmamış olması ve tekrar vida tezgahına gönderilmesi üretimde sürekli olarak bir zaman sıkıntısı yaratmıştı. Torna tezgahında işçilerin verilen iş emrine uymayarak torna makinesini gerektiğinden düşük devirde çalıştırarak işi uzattıkları ve ustaların iş başında durmayarak parça kalınlıklarını kontrol etmemesinden kaynaklanan geri dönüşler saptanmıştır. Boya tezgahında ise tornada çizilmiş parçaların üzerine 2 kat boya atılarak kaliteden geçirilmeye çalışıldığı bu yüzden daha fazla boya ve vakit harcandığı da saptanmıştır. Maliyetler açısından sıralanan sorunların hepsini aynı anda çözmek büyük zaman ve para kaybı olacağından ilk sırada olan vida tezgahı proje için seçildi.

Yapay zekalı makineyi almadan önce çevredeki iş birliği yapılan fabrikalarla (atık alüminyum satılan ve alüminyum plaka alınan) görüşülerek yapay zekalı makinelerin verimliliklerin raporlanmasını konusunda yardım istendi. Makinelerin kullanım alanları farklı olmasına rağmen makineyi alındığı takdirde sorunlu alandaki verimliliği sadece ilk etapta \%60 artıracağını tespit edilmiş oldu. Satın alma kararı onaylandığında öncelikle internet ve çeşitli yurtdışı bağlantıları kullanarak kullanıma en uygun, hurda ömrü uzun ama kalitesi en yüksek olan ve en önemlisi parça bakımlarının ülkemizde yapılabilmesi ve herhangi bir bozulma durumda tamirini ya da parça değişimini yapılabilecek bir makine aranmaktaydı. Türkiye'de Ankara da bir Alman firmasının ikame parçalarını satan değiştiren bir firma bulduğumuzda tüm dikkat Alman firmasına verildi. Firmayla iletişime geçildikten sonra ihtiyacımız doğrultusunda bir makine yapılması istendi. Çıkan bütçe ve maliyet analizleri karşılaştırılarak proje sunuldu. Proje için onay alındıktan sonra makinenin satın alım işlemini gerçekleştirildi.

Proje sahibi fabrika İstanbul'un eğimli bölgelerinden birinde olduğu için ve fabrikanın zemin çalışmaları maliyetten dolayı yapılmadığı için makineyi düz bir şekilde yerleştirmek imkânsızdı. $\mathrm{Bu}$ kadar büyük ve maliyetli bir makineyi dengesiz koymanın sonuçları ileride pahalıya mal olabileceğinden sadece makinenin kaplayacağı alanı düzleştirmek için çelik levhalar kullanılarak kısa bir platform kuruldu. Bu platform öğle yemeği saatlerinde kurularak işin aksaması önlendi. Tezgahlar biraz daha ileri alındı ve düzleşmiş alanın çevresi boş bırakıldı.

Vida tezgahındaki personeller diğer boş tezgahlara kaydırılmadan önce mesaiye bırakılarak kaydırılacakları tezgahlardaki işler öğretildi. Vida tezgahının boş kalmaması ve işlerin yavaşlamaması için personeller mesaiye dönüşümlü kalarak eğitimlerini aldılar. Bunun yanında 
makinede çalışacak personeller gerekli eğitimlere gönderildi. Onların işleri henüz olmadığ için eğitimlerini hızlı bir şekilde almaları firmamızdaki işleyişi kolaylaştırdı.

Makinenin iş takviminin nispeten daha boş olduğu bir gün gelmesini istendiği için öncelikle işçilere mesai yazılarak iş takvimindeki gecikmeler en aza indirildi. Yaklaşık 1 aylık bir sıkı çalışmanın ardından neredeyse iş takvimindeki açıklar kapanmak üzereydi.

Bu arada torna bölümündeki çalışmalar dikkatle izleniyor ve ustabaşılardan saat başı rapor alınarak makine devirleri ve işçilerin performansları düzenli olarak kontrol edildi. Projenin bitmiş olması sebebiyle; torna bölümündeki makine kontrolüne başlandı. Torna bölümündeki makineleri tek bir ara yüze bağlayarak çalışma devirlerini kontrol etme fikri üretilmişti ancak alınan yeni makinenin gelecek olması projeyi ileri bir tarihe erteleyerek daha çok ustabaşılara güvenilmesini gerektirdi.

Makinenin geldiği gün Ankara'daki ikame firmadan birkaç işçi getirilerek öğle paydoslarında 2 güne yayılarak kurulumu ve gerekli ayarları yapıldı. Kurulumun bittiği ilk gün operatörler makinenin başına getirildi ve onlara hibe edebilecekleri parçalar vererek el alışkanlığı kazanmaları sağlandı. Ankara'dan gelen firma çalışanlarının bir iki gün daha makineyi kontrol etmeleri ve izlemeleri istendi.

Bu sırada vida sıkma personelleri bakım-onarım bölümüne, boya bölümüne ve elektroliz banyo bölümüne kaydırıldı. Zaten eğitimlerini almışlardı ancak onların da ilk günlerinde hibe eşyalarla çalıştırıp el alışkanlıkları test edildi. Alınan sonuçlar herkesi memnun ettiğinde o hafta ekstra mesaileri bitirerek tekrar normal düzene dönülmüştü.

Makinenin gelmesinden 1 ay sonra tekrardan verimlilik analizi yapılarak en çok hata veren 3 tezgahı bulundu ve alınan makinenin verimlilik ölçümlerini, hata ölçümlerini ve çalışanların performans analiz çalışmaları yapıldı.

Çıkan verilere göre satın alınan makinenin vida bölümündeki hataları \% 78 oranında azalttı̆ğ ve iş hızını \%34 arttırarak iş takvimindeki gecikmelerin çoğunun ortadan kaldırıldığı görüldü. Proje başarıyla sonuçlandı.

Torna bölümündeki insan hatasının yine ufak bir artış göstermekte olduğu anlaşıldı. Sorun bulunan tezgahlar/bölümlerde vida bölümünün olmadığını görüldü. Sorunlu tezgahlar sırasıyla; torna tezgahı, boya bölümü ve ışıl işlem tezgahı olarak belirlendi.

\section{TARTIŞMALAR VE ÖNERİLER}

Çalışmamızda firmamızdaki yıllardır aynı olan makinelerin değişsiminin ilk adımı atılmış oldu. Bir makinenin insan gücünün yerine geçerek daha verimli bir iş çıkartabileceğini görüldü. Örneğin; verimlilik karşılaştırmalarını yapıldığında; görülebileceği gibi yapay zekalı makinenin firmamızdaki hataların giderilmesinde $\% 78$ fayda sağladığ 1 görülmüştür. Buna karşılık düşünmemiz gereken tek bir soru vardır. Daha mükemmel yapmanın yolu nedir? Eğer bu soruya cevap bulunabilirse ki bunda gelişen teknolojiyi takip ederek ve firmamızın bu zamana kadar yaptığı verimlilik testlerinden daha detaylı bir çalışma ortaya koyulursa her zaman daha iyiye gitmenin bir yolu olacaktır.

Elbette her yüksek verimliliğin bir bedeli de olacaktır. Bu projede ödenen bedel paranın yanı sıra daha sıkı bir çalışma takvimi ve yeni teknolojiye ayak uydurmakta geç kalmış olmaktan 
kaynaklanan alışma süreciydi. Önce maddi kaybı ele alacak olursak; yapılmasını istenen makine oldukça pahalı ve üst seviyeydi. Bu yüzden proje mali konuda epeyce düşündürmüştü. Ancak projeye bir şans verilmezse hatalardan, iş kazalarından, fazla mesai ücretlerinden ya da işçilerin yeterli sayıda olmamasından dolayı oluşacak olan maliyet bundan çok daha fazla olacaktı. Uzun dönem için getirisinin yüksek bir proje olmasından cesaret alarak işe başlandı. Proje sonlandığında kaybedilen onca zamanın ne kadar olumlu bir şekilde döneceğini görüldü. Ama her zaman daha fazla soruyla hiç bitmeyecek sorunlar dizisini çözmeye çalışırken yapay zekadan yardım almaya devam ederek en kısa sürede en yüksek sonuç verim alınmaya çalışılmalıdır.

\section{SONUÇ}

Yapılan uygulamanın ardından yapay zekanın esnek imalat üretimde sağladığı katkının oldukça fazla olduğu görülmüştür. İnsan gücünün yerine makine gücünün gerektiği yerlerde insanlardan daha verimli oldukları özellikle güç isteyen ve küçük insan hatalarının büyük maliyetlere yol açtıkları bölümlerde yapay zekalı makinelerin iş yükünü insanlardan devralmasının yararlı olduğu görülmüştür. $\mathrm{Bu}$ yararı şirketimizdeki iş kazalarının ya da montaj hattından hatalı olarak çıkan ürünlerimizin azalmış olmasından görülmüştür.

Bu çalışmayla birlikte; firmamızda aslında göremediğimiz sorunlar görülmüştür. Bu sorunlardan birinci öncelikli olan montaj hattı sorunu büyük ölçüde çözüme kavuşturularak çözülmesi gereken diğer problemlere de alternatif bir kapı aralamıştır. Projemiz baştan sona kadar alınabilecek bütün veriler kullanılarak ve bu verilerin içinden büyük bir titizle veri madenciliği yapılarak sürdürüp sonuca erdirilmiştir. Firmamız projenin başarı sonuçlanmasının geri dönüşünü hızla almıştır. Takvimdeki gecikmelerin ve iş kazalarının azalmasıyla işler ek mesailer olmamasına rağmen daha hızlı, tam kadrolu ve daha koordineli bir şekilde sürdürülmüştür. Verimlilik analizlerinin de gösterdiği gibi; yapay zekalı makine proje sürerken bile çalışmalarıyla birçok kapıyı aralayarak, kendi maliyetini firmaya geri kazandırmaya başlamıştır. Bunun dışında makinenin güçlü ve verimli olmasının bir diğer faydası bakım-onarım tezgahına gelen ürünlerin azalmasından da görülmüştür. Yapay zeka hayatımıza girdiğinden beri her zaman hayatımızın bir köşesine dokunacaktır. Sadece bu kez bir çocuğu daha hızlı mutlu etmemize olanak sağlamıştır.

\section{KAYNAKLAR}

1. Okan OKUTKAN, Yüksek Lisans Tezi,Yapay Zeka İle Mobil Robot Kontrolu, İstanbul Teknik Üniversitesi, Fen Bilimleri Enstitüsü,2006

2. İlhan Asiltürk, Doktora Tezi, Testere İle Kesme İşleminde Yapay Zeka Tabanlı Adaptif Kontrol Uygulaması, Makina Mühendisliği Anabilim Dalı, Konya Selçuk Üniversitesi Fen Bilimleri Enstitüsü,2007

3. Pirim A . YAPAY ZEKA. Journal of Yaşar University. 2006; 1(1): 81-93.

4. Yeliz ŞENKAYA, Uğur Güven ADAR, Makale, Siber Savunmada Yapay Zeka Sistemleri Üzerine İnceleme, 2014

5. Yılmaz Gökşen, Geleneksel Üretimden Esnek Üretime: Karşılaştırmalı Bir İnceleme, Dokuz Eylül Üniversitesi, Sosyal Bilimler Enstitüsü Dergisi: 2003; 5-4

6. Sağıroğlu ve Arkadaşları, Yoğun Bakım Ünitesinde Perkütan ve Cerrahi Trakeostominin Karşılaştırılması, Klinik Araştırma, Göztepe Tıp Dergisi 25(2):67-70, 2010 
7. Duygu İÇEN, Süleyman GÜNAY, İstatikçiler Dergisi \& İstatistik Aktüerya, Uzman Sitemler ve İstatistik 7: 2014; 37-45

8. N. ALLAHVERDİ, Uzman Sistemler Bir Yapay Zeka Uygulaması, Atlas Yayın Dağıtım, Ankara; 2002

9. RONALD G. Askin ve CHARLES R. Standridge Modelling Analysis Of Manufacturing Systems, Wiley, USA 1993

10. GROOVER, P. Mikel, Automation Production Systems and Computer Integrated Manufacturing, Prentice- Hall Inc , USA 1987 